University of Nebraska - Lincoln

DigitalCommons@University of Nebraska - Lincoln

May 1990

\title{
Fabrication of ferromagnetic and antiferromagnetic chromium oxides by organometallic chemical vapor deposition
}

\author{
Peter A. Dowben \\ University of Nebraska-Lincoln, pdowben@unl.edu \\ Yoon Gi Kim \\ Syracuse University \\ S. Baral-Tosh \\ Syracuse University \\ G.O. Ramseyer \\ General Electric Company, Electronics Laboratory, Electronics Park, Syracuse, New York \\ Chanyong Hwang \\ University of Wisconsin, Madison
}

See next page for additional authors

Follow this and additional works at: https://digitalcommons.unl.edu/physicsdowben

Part of the Physics Commons

Dowben, Peter A.; Kim, Yoon Gi; Baral-Tosh, S.; Ramseyer, G.O.; Hwang, Chanyong; and Onellion, M., "Fabrication of ferromagnetic and antiferromagnetic chromium oxides by organometallic chemical vapor deposition" (1990). Peter Dowben Publications. 104.

https://digitalcommons.unl.edu/physicsdowben/104

This Article is brought to you for free and open access by the Research Papers in Physics and Astronomy at DigitalCommons@University of Nebraska - Lincoln. It has been accepted for inclusion in Peter Dowben Publications by an authorized administrator of DigitalCommons@University of Nebraska - Lincoln. 


\section{Authors}

Peter A. Dowben, Yoon Gi Kim, S. Baral-Tosh, G.O. Ramseyer, Chanyong Hwang, and M. Onellion 


\title{
Fabrication of ferromagnetic and antiferromagnetic chromium oxides by organometallic chemical vapor deposition
}

\author{
P. A. Dowben, ${ }^{\text {a) }}$ Yoon Gi Kim, and S. Baral-Tosh \\ Department of Physics and the Center for Molecular Electronics. Syracuse University, \\ Syracuse, New York 13244-1130 \\ G. O. Ramseyer \\ General Electric Company, Electronics Laboratory, Electronics Park, P. O. Box 4840, \\ Syracuse, New York 13221 \\ Chanyong Hwang and $M$. Onellion ${ }^{a)}$ \\ Department of Physics, University of Wisconsin, Madison, Madison, Wisconsin 53706
}

We have been able to fabricate $\mathrm{CrO}_{2}$ and $\mathrm{Cr}_{2} \mathrm{O}_{3}$ from ultraviolet photolytic and plasma-assisted decomposition of $\mathrm{Cr}(\mathrm{CO})_{6}$ in an oxygen carrier gas. The composition of these films is uniform in composition and contains little contamination. Using magneto-optic Kerr effect measurements, we have been able to demonstrate that the $\mathrm{CrO}_{2}$ films are ferromagnetic

\section{INTRODUCTION}

The decomposition of the hexacarbonyls, $M(\mathrm{CO})_{6}$ (where $\mathrm{M}$ is $\mathrm{Cr}, \mathrm{Mo}$, or $\mathrm{W}$ ), to form metal thin films has been the subject of a great number of studies.' While a number of investigations have been directed toward fabricating chromium films from the decomposition of chromium hexacarbonyl, the quality of the resulting films has varied from films with only limited amounts of oxygen contamination (less than $7 \%$ oxygen and $0.8 \%$ carbon $)^{2,3}$ to the more typical films with large amounts of oxygen and carbon contamination..$^{4-9}$ The propensity for films formed from the decomposition of chromium hexacarbonyl to incorporate contaminants, particularly oxygen, ${ }^{6,9}$ during film growth can be exploited to form technologically important thin-film materials. In particular, we have chosen to promote the incorporation of oxygen by decomposing chromium hexacarbonyl in an oxygen atmosphere.

The selected area deposition of $\mathrm{CrO}_{2}$ thin films, possible with organometallic chemical vapor deposition, is important because $\mathrm{CrO}_{2}$ is a ferromagnetic compound at room temperature with a Curie temperature $118^{\circ} \mathrm{C}$ (Ref. 10) with a number of technological applications. Furthermore, this compound can be demagnetized with little input of energy and has pronounced magneto-optic properties in the visible including a substantial Kerr effect. ${ }^{11}$

\section{EXPERIMENT}

The chromium oxide films were deposited by photolytic and plasma deposition of $\mathrm{Cr}(\mathrm{CO})_{6}$ in ambient oxygen atmosphere. The $\mathrm{Cr}(\mathrm{CO})_{6}$ was introduced into each vacuum system from the sublimation of the crystalline solid, whose vapor pressure is given by ${ }^{8.12}$

$$
\log _{10} P=10.63-3285 / T \text {, }
$$

where $P$ is the pressure in Torr, and $T$ is the temperature of the hexacarbonyl in degrees Kelvin.

"Address correspondence to either of these authors.
The vacuum system for pyrolytic and photolytic CVD has been described elsewhere. ${ }^{13,14}$ The photolytic decomposition of $\mathrm{Cr}(\mathrm{CO})_{6}$ was performed with a commercial ( Molectron) pulsed nitrogen laser in the near ultraviolet (337 $\mathrm{nm}$ ). The power output of the laser was $330 \mathrm{nW}$ with a peak output of $450 \mathrm{~kW}$ or $4.5 \mathrm{~mJ} /$ pulse. The beam dimension was $6 \mathrm{~mm} \times 32 \mathrm{~mm}$ and focused through a quartz window on a silicon wafer to a $0.4 \mathrm{~mm} \times 2.1 \mathrm{~mm}$ area. The substrate hold er was a solid copper block which could be cooled with chilled water. Photolytic deposition times ranged in periods from 3 to $48 \mathrm{~h}$. The background pressure in this all-glass vacuum system was approximately $10{ }^{5}$ Torr. The organometallic complexes were admitted to a pressure no more than $10 \mathrm{~m}$ Torr.

Chromium oxides were also deposited using a 13.56 $\mathrm{MHz}, 200-\mathrm{W}$ rf plasma. This system could reach a base pressure of $10^{-3}$ Torr. The silicon substrates could be heated by a cartridge heater to a temperature of 150 and $300{ }^{\circ} \mathrm{C}$. A continuous flow system was used with all deposition techniques, with an oxygen carrier gas supplying additional background pressure. The plasma assisted deposition chamber is schematically shown in Fig. 1

The coatings were examined while still in place on the silicon by scanning microscopy (SEM), $x$-ray emission spectroscopy (XES or EDAX), Auger electron spectroscopy (AES), and magneto-optic Kerr effect (MOKE). In order to determine the composition of the films produced either by rf plasma-assisted deposition or by laser-assisted deposition, Auger depth profiling was undertaken using a commercial Perkin-Elmer Auger electron spectroscopy system. The determination of the film thickness was undertaken using a commercial mechanical film thickness probe (Talysurf 4 ).

The magneto-optic Kerr effect measurements were performed using a 5-mW He-Ne laser, two crossed polarizers, and a chopper wheel run at $800 \mathrm{~Hz}$. All measurements were performed in air. The maximum applied magnetic field was $1500 \mathrm{Oe}$, and the applied field was changed at the rate of 15 $\mathrm{Oe} / \mathrm{s}$. The signal was obtained using a lock-in amplifier. The light was detected using a photodiode and transduced to a voltage. 


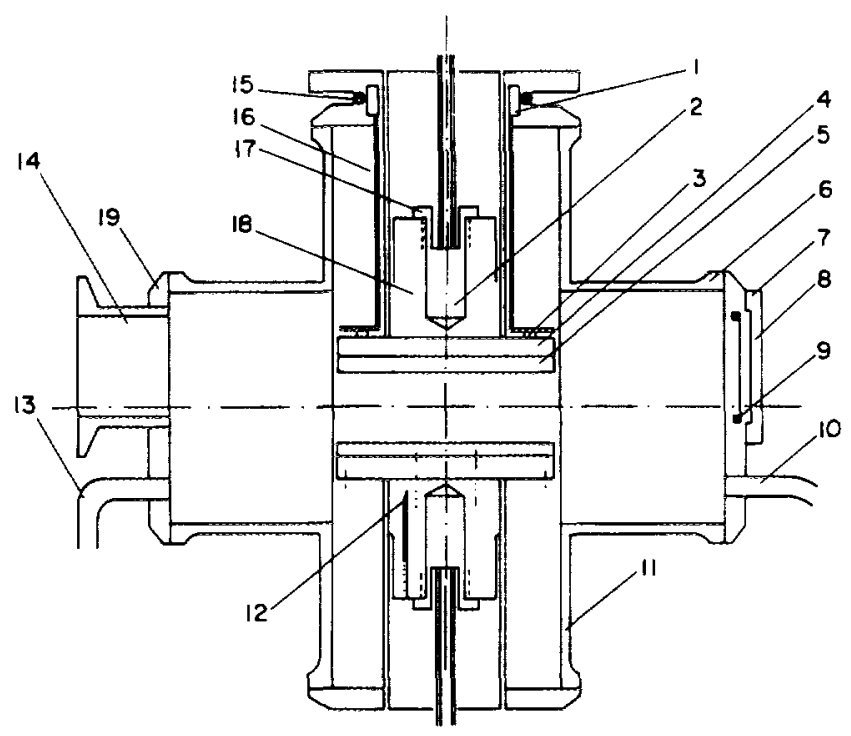

FIG. 1. A schematic diagram of the plasma reactor. Various parts of the plasma reactor are identified as (1) ceramic certering ring, (2) cartridge heater, (3) ceramic certering ring for cathode ground shield, (4) cathode pedestal, (5) substrate, (6) vacuum vessel, (7) window flange, (8) window, (9) window seal, (10) gas inlet for plasma, (11) ground shield, (12 thermocouple, (13) pressure gauge, (14) pump outlet, (15) vacuum seal, (16) cathode ground shield, (17) cartridge heater clamp, (18) cathode feedthrough, and (19) modular flange assembly.

\section{PHOTOLYSIS}

The great potential of photolytic deposition of $\mathrm{Cr}(\mathrm{CO})_{6}$ is that photolysis of surface species may be used for selective area processing. ${ }^{1-7.9} \mathrm{We}$ have been able to selectively deposit $\mathrm{Cr}_{2} \mathrm{O}_{3}$ using $1 \mathrm{mT}$ Torr oxygen and $10 \mathrm{mTorr}$ of $\mathrm{Cr}(\mathrm{CO})_{6}$ with the laser decomposition from a nitrogen laser. The formation of $\mathrm{CrO}_{2}$ requires far higher partial oxygen pressures.

From our Auger electron spectroscopy results, it is clear that both $\mathrm{Cr}_{2} \mathrm{O}_{3}$ and $\mathrm{CrO}_{2}$ can be formed (Fig. 2). The composition of the films with depth into the film has been investigated by ion milling of the film with $\mathrm{Ar}^{+}$-ion bombardment
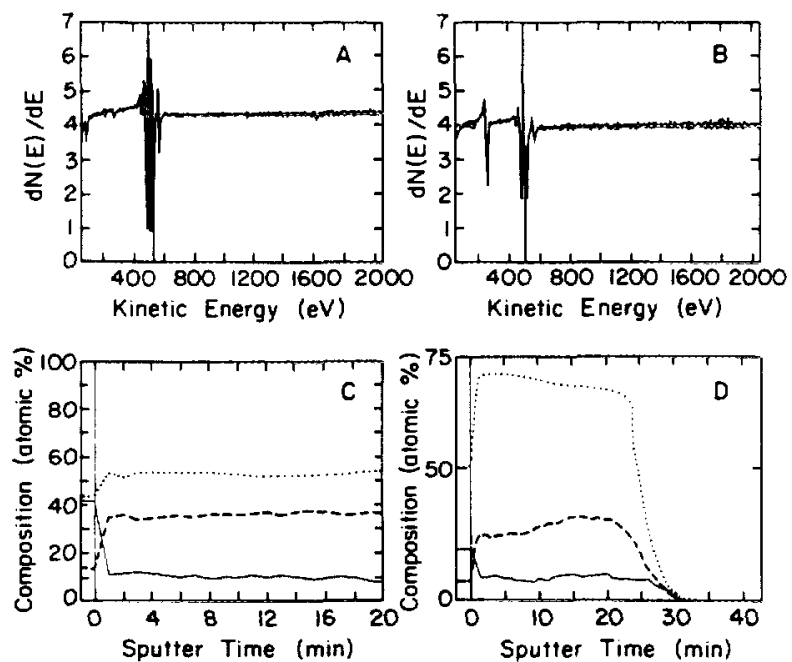

FIG. 2. Auger electron spectra of (a) $\mathrm{Cr}_{2} \mathrm{O}_{3}$ and (b) $\mathrm{CrO}_{2}$ films fabricated from the photolysis of $\mathrm{Cr}(\mathrm{CO})_{6}$ in oxygen at $337 \mathrm{~nm}$. Auger electron spec troscopy depth profile provides a strong indication that these films have a uniform composition for the (c) $\mathrm{Cr}_{2} \mathrm{O}_{3}$ and (d) $\mathrm{CrO}$. and compositional analysis with Auger electron spectroscopy. These Auger depth profiling studies show that the films fabricated by the laser assisted decomposition of $\mathrm{Cr}(\mathrm{CO})_{6}$ in any oxygen atmosphere are uniform except for an interfacial region in the vicinity of the silicon substrate surface (Fig. 2). Earlier studies have shown that $\mathrm{Cr}_{2} \mathrm{O}_{3}$ is readily formed ${ }^{9}$ via laser-assisted decomposition of the chromium hexacarbonyl. There have also been early indications that chromium dioxide could be formed as well. ${ }^{\circ}$ The results, outlined in Fig. 2, demonstrate that both oxides can be readily formed reproducibly into reasonably isotropic films.

We have observed that the rate of chromium deposition can differ by a factor of 3 over $6^{\circ}(288-294 \mathrm{~K})$, under identical conditions, for different substrate temperatures using XES as a measure of film thickness. This is a strong indication that the decomposition process is a surface process. At lower temperatures, the surface lifetime of the organometallic species is much longer, and the probability of being able to remove a carbonyl ligand rather than initiate desorption into vacuo may be reasonably expected to be greater. Given the bond strength of the carbonyl ligands to the metal' ${ }^{1}$ and the results of surface studies with a variety of carbonyls (see, for example, Ref. 15 and 16), it is clear that the laser decomposition of the chromium hexacarbonyl occurs through the sequential removal of carbonyl ligands, even with radiation in the ultraviolet (in our case, $337 \mathrm{~nm}$ )

For very rapid thin-film growth, where selective area processing is not required, plasma-assisted deposition of chromium oxides can be undertaken, as discussed below.

\section{PLASMA-ASSISTED DEPOSITION}

By operating the plasma reactor at $10-\mathrm{W}$ power, with the sample temperature of $242^{\circ} \mathrm{C}$ and a $\mathrm{Cr}(\mathrm{CO})_{6}$ pressure of $10 \mu$, a chromium oxide film can be deposited. With a partial pressure of oxygen between 3 and $15 \mu$, we have found that the film composition is uniformly $\mathrm{Cr}_{2} \mathrm{O}_{3}$ as determined by Auger depth profiling. Fabrication of $\mathrm{CrO}_{2}$ requires oxygen partial pressures greater than $15 \mu$.

In spite of the very large number of competing reactions expected in plasma-assisted decomposition of $\mathrm{Cr}(\mathrm{CO})_{6}$,' 'sequential carbonyl ligand removal does appear to occur and the films are surprisingly free of contamination as seen in Fig. 3. Mass spectroscopy studies of the metal hexacarbon$y / s^{1.14}$ clearly indicate that the sequential removal of carbonyl ligands is the preferred decomposition route under electron impact. We believe that, as with most plasma-assisted decomposition processes, electron impact is one of the most important decomposition mechanisms. Very little carbonyl incorporation is observed to occur in spite of the very rapid rate of film growth. The rate of thin-film growth under our operating conditions is approximately $30 \AA / \mathrm{min}$.

MOKE studies were undertaken of these films, and the $\mathrm{CrO}_{2}$ films provided some evidence for ferromagnetism. While the signal level was satisfactory for MOKE, the signal-to-noise ratio was poor as a result of scattered light from the thin-film surface. Nonetheless, the hysteresis loop for $\mathrm{CrO}_{2}$ obtained from MOKE does show that these films are 

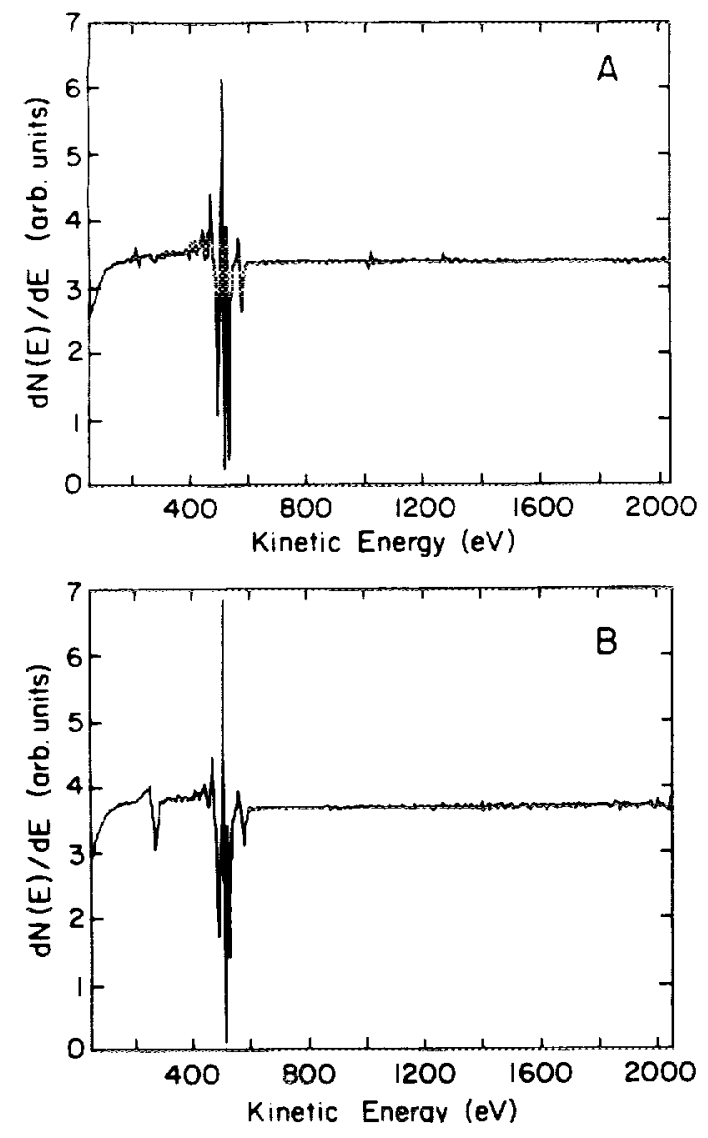

FIG. 3. Auger electron spectra of (a) $\mathrm{Cr}, \mathrm{O}$, and (b) $\mathrm{CrO}$, of films made from the plasma-assisted decomposition of $\mathrm{Cr}(\mathrm{CO})$, in an oxygen atmosphere.

ferromagnetic, as seen in Fig. 4. Both the MOKE hysterisis loop and the Auger electron spectroscopy studies of composition provide clear indications that we can form antiferromagnetic chromium oxides. This can be accomplished by raising the temperature of the substrate and/or lowering the oxygen partial pressure within the plasma. These films are also uniform in composition.

We have observed that the $\mathrm{CrO}_{2}$ films are not uniformly ferromagnetic and have a wide range of coercivities. Indeed, some areas of these films appear to be antiferromagnetic. At present, these results are not completely understood, and we

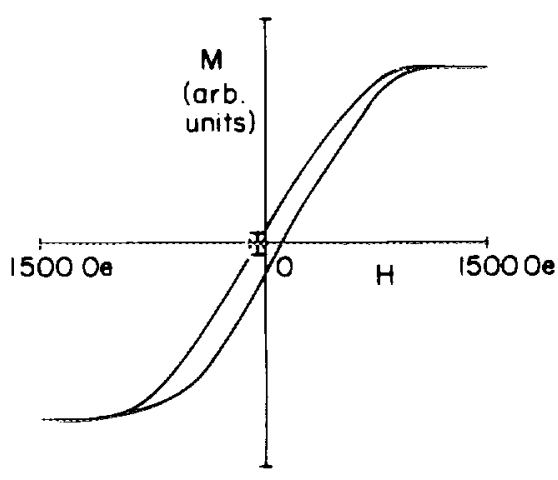

FIG. 4. The hysterisis loop obtained from magneto-optic Kerr effect. Magnetization is plotted against applied magnetic field. need to identify the precise conditions for making $\mathrm{CrO}_{2}$ films that have uniform ferromagnetic properties as well as uniform composition. Auger electron spectroscopy studies provide some evidence for oxygen and chromium interdiffusion. Given that the $\mathrm{Cr}_{2} \mathrm{O}_{3}$ oxide is more stable at the temperatures of our thin-film growth, ${ }^{10}$ it is not surprising that we observe $\mathrm{Cr}_{2} \mathrm{O}_{3}$ precipitates at the chromium oxide-silicon interface. These chromium oxide islands may contribute to the nonuniform ferromagnetic properties of our films, as observed in our MOKE studies.

Scanning tunneling microscope studies of these films are in progress to study their morphology on an atomic scale. ${ }^{17}$

\section{CONCLUSION}

We have demonstrated using MOKE that ferromagnetic $\mathrm{CrO}_{2}$ films can be fabricated from the decomposition of $\mathrm{Cr}(\mathrm{CO})_{6}$ in an oxygen atmosphere. The advantages of this type of thin-film fabrication are the very low processing temperatures and the potential for selective area processing. The films can be fabricated with surprisingly little contamination and considerable compositional uniformity. Silicon does not, however, appear to be an ideal substrate as a result of interdiffusion or chemical reactions that occur at the silicon chromium oxide interface.

\section{ACKNOWLEDGMENTS}

This work was funded by the AFOSR through Contract No. F30602-88-D-0027 administered by Rome Air Development Center as task No. A-9-1913. We would also like to thank Professor E. Schiff for his help and assistance.

'P. A. Dowben, J. T. Spencer, and G. T. Stauf, Mater. Sci. Eng. E 2, 297 (1989).

${ }^{2}$ R. Solanki, P. K. Boyer, and G. J. Collins, Appl. Phys. Lett. 41, 1048 (1982).

'P. K. Boyer, C. A. Moore, R. Solanki, W. K. Ritchie, G. A. Roche, and G. J. Collins, in Laser Diagnostic and Photochemical Processing for Semiconductor Devices, edited by R. M. Osgood, S. R. J. Brueck, and H. R Schlossberg, Meter. Res. Soc. Symp. Proc. 17, 119 (1983)

${ }^{4}$ T. M. Mayer, G. J. Fisanick, and T. S. Eichelberger, J. Appl. Phys. 53. 8462 (1982).

${ }^{5}$ H. Yokoyama, F. Uesugi, S. Kishida, and K. Washio, Appl. Phys. A 27. 25 (1985).

${ }^{6}$ R. L. Jackson, G. W. Tyndall, and S. D. Sather, Appl. Surf. Sci. 36, 119 (1989).

' R. W. Bigelow, J. G. Black, C. B. Duke, W. R. Salaneck, and H. R. Thom as, Thin Solid Films 94, 233 (1982).

${ }^{8}$ B. B. Owen and R. T. Webber, Trans. Am. Inst. Min. Metall. Pet. Eng. 175,693 (1948)

${ }^{9}$ K. A. Singmaster, F. A. Houle, and J. R. Wilson, in Chemical Perspectives of Microelectronic Materials, edited by M. E. Gross, J. Jasinski, and J. Yates, Mater. Res. Soc. Symp. Proc. 131, 469 (1989).

${ }^{10}$ B. L. Chamberland, CRC Crit. Rev. Solid State Mater. Sci. 7, 1 (1977),

"A. M. Stoffel, J. Appl. Phys. 40, 1238 (1969).

${ }^{12}$ J. J. Lander and L. H. Germer, Trans. Am. Inst. Min. Metall. Pet. Eng. $175,648(1942)$.

${ }^{13}$ G. T. Stauf, D. C. Driscoll, P. A. Dowben, S. Barfuss, and M. Grade, Thin Solid Films 153, 421 (1987)

${ }^{14}$ S. Varma Y. G. Kim, Z. Psenicnik, P. A. Dowben, and R. R. Birge, Materials, Metals and Minerals Society, TMS Proceedings (1990) (in press). ${ }^{15}$ T. A. Germer and W. Ho, J. Chem. Phys. 89, 562 (1988).

${ }^{16}$ C. M. Friend, J. R. Swanson, and F. A. Flisch, in Chemical Perspectives of Microelectronic Moterials, edited by M. E. Gross, J. Jasinski, and J. Yates, Mater. Res. Soc. Symp. Proc. 131, 461 (1989).

" K. Perkins, C. Hwang, M. Onellion, and P. A. Dowben (in preparation). 